\title{
Irbesartan improves arterial compliance more than lisinopril
}

\author{
This article was published in the following Dove Press journal: \\ Vascular Health and Risk Management \\ 13 July 2009 \\ Number of times this article has been viewed
}

\section{Khalid Ali' \\ Chakravarthi Rajkumar' \\ Francesco Fantin ${ }^{2}$ \\ Rebekah Schiff $^{3}$ \\ Christopher J Bulpitt ${ }^{3}$}

'Academic Department of Geriatrics, Brighton and Sussex Medical School, Brighton, UK; ${ }^{2}$ Department of Geriatrics, University of Verona, Italy; ${ }^{3}$ Section of Geriatric Medicine, Imperial College School of Medicine, London, UK
Correspondence: Khalid Ali

Academic Department of Geriatrics,

Brighton and Sussex Medical School,

Audrey Emerton Building, Eastern Road,

Brighton BN2 5BE, UK

Tel $+44(0) 1273523360$

Fax +44 (0) 1273523366

Email khalid.ali@bsuh.nhs.uk
Background: Antihypertensive agents can reduce arterial stiffness. We hypothesized that an angiotensin receptor blocker (ARB) irbesartan and an angiotensin converting enzyme inhibitor (ACEI) lisinopril improved arterial compliance.

Methods: A randomized, double-blind, double-dummy, controlled crossover trial. Fifteen hypertensive patients, mean age $65.5 \pm 8.9$ years (mean $\pm \mathrm{SD}$ ) were given irbesartan ( 150 to $300 \mathrm{mg} /$ day) or lisinopril (10 to $20 \mathrm{mg}$ /day) for 12 weeks and then crossed over for 12 weeks. Pulse wave velocity (PWV) in the carotid-femoral (CF), carotid-radial (CR), and femoral dorsalis-pedis (FD) were measured using a Complior ${ }^{\circledR}$ PWV system.

Results: After 12 weeks, systolic blood pressure (SBP) decreased from $162.4 \pm 12.9$ to $134.5 \pm 14.8$ with irbesartan and to $145.2 \pm 25 \mathrm{mmHg}$ with lisinopril. Irbesartan and lisinopril reduced PWV $(\mathrm{CF})$ in the elastic arterial system from $15.1 \pm 5$ to $13.3 \pm 2.6(\mathrm{p}<0.005)$ and to $14 \pm 4.7(\mathrm{p}<0.05) \mathrm{m} / \mathrm{s}$ respectively $(\mathrm{p}=0.345)$. Irbesartan reduced PWV $(\mathrm{CR})$ and PWV (FD), whereas lisinopril did not. The difference between treatments was significant after SBP adjustment ( $\mathrm{p}=0.037$ for PWV (CR) and $\mathrm{p}<0.001$ for PWV (FD)).

Conclusions: Irbesartan improved arterial compliance in elastic and muscular arteries, whereas lisinopril improved it only in elastic arteries.

Keywords: arterial compliance, angiotensin receptor blockers, ACE inhibitors, hypertension

\section{Introduction}

Hypertension is one of the most important risk factors for cardiovascular diseases and is associated with increased morbidity and mortality. ${ }^{1}$ It is known that the treatment of hypertensive subjects reduces the diseases associated with hypertension, for example stroke and coronary artery disease. ${ }^{2,3}$ Despite this favorable effect of antihypertensive treatment, the incidence of cardiovascular diseases remains higher in treated hypertensives than in matched controls with similar blood pressure (BP) levels, ${ }^{4}$ suggesting the presence of other additional risk factors, such as previous vascular damage, which may be represented by a decreased arterial compliance. Increased arterial stiffness in particular as assessed by pulse wave velocity (PWV), is an independent marker of cardiovascular disease in hypertensive subjects and is linked to ventricular hypertrophy and atherosclerosis. ${ }^{5-9}$ It is also higher in patients with end stage renal disease and diabetes. ${ }^{10-12}$ Changes in arterial compliance have been used to assess the effect of some therapies. ${ }^{13,14}$

Angiotensin II plays an important role in development of an increased BP and also tissue damage. The two categories of drugs acting on the renin-angiotensin system have been shown to have beneficial effects on BP, heart and arteries. The inhibition 
of angiotensin-converting enzyme (ACE) can provide a protective effect on the adverse changes due to hypertension and prevent cardiovascular outcomes, possibly more than is achieved with diuretic based-therapy. ${ }^{15}$ Treatment with ACE inhibitors increases arterial distensibility ${ }^{16}$ and drugs blocking the angiotensin II receptor have been shown to improve endothelial function and increase arterial compliance of small and large arteries in addition to their antihypertensive effect. ${ }^{17-19}$ It has been suggested that both valsartan and captopril reduce the pulse wave velocity (PWV) and Augmentation Index by a similar amount in essential hypertension. ${ }^{20}$

The purpose of this study was to assess the effect of an angiotensin receptor blocker (ARB), irbesartan, and an ACE inhibitor (ACEI), lisinopril, on arterial compliance, comparing the effects of these two antihypertensive drugs on different arterial segments, one predominately elastic and the other predominately muscular.

\section{Methods}

\section{Study population}

We performed a randomized, double-blind, double-dummy, controlled crossover trial. Fifteen hypertensive patients without cardiovascular complications, mean age $65.5 \pm 8.9$ years (mean $\pm \mathrm{SD}$ ) were recruited. They were all nonsmokers. They were randomly allocated to receive irbesartan (150 to $300 \mathrm{mg} /$ day) or lisinopril (10 to $20 \mathrm{mg} /$ day) for 12 weeks and then immediately crossed over for a further 12 weeks.

The study was approved by the Ethics Committee of the Hammersmith Hospital Trust, London UK.

\section{Exclusion criteria}

We excluded subjects on hormone replacement therapy or with a history of cardiac failure or valvular heart disease. Subjects with contraindications to an ACEI or ARB were also excluded.

\section{Study design}

Patients who were currently taking antihypertensive medication had this stopped for 2 weeks prior to the screening visit, while having their BP monitored regularly. Between the screening and baseline visit, BP was measured once a week for 3 weeks. On these occasions the mean of three measurements was recorded and used for fulfilling the study entry criteria, ie, sitting systolic BP $(\mathrm{SBP})>160 \mathrm{mmHg}$ and/or sitting diastolic BP (DBP) $>90 \mathrm{mmHg}$.
At the screening visit written informed consent was obtained and medical history recorded. Lying, sitting and standing BP were measured and a physical examination performed. PWV and BP were recorded at the baseline visit and were repeated at 12 and 24 weeks.

The initial treatment was $150 \mathrm{mg}$ irbesartan or $10 \mathrm{mg}$ lisinopril. These were titrated to $300 \mathrm{mg}$ and $20 \mathrm{mg}$ respectively at weeks 6 and 18 if the SBP $>160 \mathrm{mmHg}$ and/or the DBP was $>90 \mathrm{mmHg}$. At week 12, the patients were crossed over and received the other drug.

\section{Statistical analysis}

The baseline data are presented as means \pm standard deviation. Data were analyzed according to the method for crossover trials described by Senn ${ }^{21}$ using SAS Version 8. Parametric data were analyzed by means of a matched paired t-test with adjustment for any period effect and a test for carry-over. PWV readings were converted for a standardized reading of $150 \mathrm{mmHg}$ and repeat t-test was performed between the two groups to eliminate any effect of BP on PWV.

\section{Procedures}

Baseline characteristics were measured (Table 1).

\section{Blood pressure (BP)}

The average of three BP readings at the brachial artery, taken at 5-minute intervals, in the right upper arm of the supine subject, was performed using an Omron HEM-705CP automatic BP recording unit.

Table I Characteristics of the study population at baseline

\begin{tabular}{lll}
\hline & Mean \pm SD & Range \\
\hline Age (years) & $65.1 \pm 9.5$ & $53-80$ \\
Systolic blood pressure $(\mathrm{mmHg})$ & $162.4 \pm 12.9$ & $135-178$ \\
Diastolic blood pressure $(\mathrm{mmHg})$ & $98.7 \pm 8.1$ & $82-110$ \\
PWV carotid-femoral $(\mathrm{m} / \mathrm{s})$ & $15.1 \pm 5.0$ & $9.3-29.3$ \\
PWV carotid-radial $(\mathrm{m} / \mathrm{s})$ & $12.4 \pm 2.3$ & $9.4-16.8$ \\
PWV femoral-dorsalis pedis $(\mathrm{m} / \mathrm{s})$ & $11.0 \pm 2.6$ & $7.3-17.2$ \\
Triglycerides (mmol/L) & $1.9 \pm 0.98$ & $1.0-5.0$ \\
Cholesterol (mmol/L) & $6.2 \pm 1.47$ & $3.6-9.2$ \\
LDL cholesterol (mmol/L) & $4.1 \pm 1.44$ & $1.2-6.6$ \\
HDL cholesterol $(\mathrm{mmol} / \mathrm{L})$ & $1.28 \pm 0.68$ & $0.5-3.5$ \\
Height $(\mathrm{cm})$ & $166.3 \pm 9.4$ & $152-18 \mathrm{I}$ \\
Weight $(\mathrm{kg})$ & $77.8 \pm 15.7$ & $47-96$ \\
BMI $\left(\mathrm{kg} / \mathrm{m}^{2}\right)$ & $28.4 \pm 5.2$ & $20.4-38.4$ \\
\hline
\end{tabular}

Abbreviations: BMI, body mass index; PWV, pulse wave velocity; LDL cholesterol, low-density lipoprotein cholesterol; HDL, high-density lipoprotein cholesterol. 


\section{Pulse wave velocity (PWV)}

PWV in the central, elastic arteries (carotid-femoral region) and the peripheral, muscular arteries (carotid-radial and femoral-dorsalis pedis regions) were determined using a Complior $^{\circledR}$ (Colson Medicals, Paris) PWV recording unit. ${ }^{22}$ Two sensors were positioned, one at the base of the right common carotid artery and one over the radial artery, similarly over the right common carotid artery and the right femoral artery and over the right femoral artery and the ipsilateral dorsalis pedis artery, thereby continuously measuring pulse wave signals. Distances between the two applanation sites were measured as a straight line between these points on the skin surface, using a tape measure. The time interval between the feet of two simultaneously recorded waves at the two applanation sites was determined and PWV was calculated.

\section{Results}

The characteristics of study population are shown in Table 1 . We studied 15 patients ( 7 women and 8 men).

After 12 weeks of treatment SBP decreased from $162.4 \pm 12.9 \mathrm{mmHg}$ to $134.5 \pm 14.8 \mathrm{mmHg}(\mathrm{p}<0.05)$ with irbesartan and to $145.2 \pm 25 \mathrm{mmHg}(\mathrm{p}<0.05)$ with lisinopril and DBP from $98.7 \pm 8.1 \mathrm{mmHg}$ to $78.6 \pm 9.2 \mathrm{mmHg}$ $(\mathrm{p}<0.05)$ and to $84.1 \pm 11.6 \mathrm{mmHg}(\mathrm{p}<0.05)$ with lisinopril (Table 2, Figure 1). There was a trend to significant differences in the decrease of SBP and DBP between the two drugs $(\mathrm{p}=0.08)$.

We found a significant decrease of PWV (C-F) for both drugs after 12 weeks of treatment. The PWV (C-F) decreased from $15.1 \pm 5 \mathrm{~m} / \mathrm{s}$ to $13.3 \pm 2.6 \mathrm{~m} / \mathrm{s}(\mathrm{p}<0.005)$ and to $14 \pm 4.7 \mathrm{~m} / \mathrm{s}(\mathrm{p}<0.05)$ with irbesartan and lisinopril respectively (Table 2). The effects of the two treatments were not statistically significantly different $(p=0.345)$.

We found significant decrease of PWV (F-D) for irbesartan, but not for lisinopril. The PWV (F-D) decreased after treatment with irbesartan from $11 \pm 2.6 \mathrm{~m} / \mathrm{s}$ to $10.1 \pm 2.6 \mathrm{~m} / \mathrm{s}(\mathrm{p}<0.05)$ (Table 2). This difference between the treatments was statistically significant before $(p=0.01)$ and after $(\mathrm{p}<0.001)$ adjustment for $\mathrm{SBP}=150 \mathrm{mmHg}$.

PWV (C-R) after 12 weeks of treatment changed from $12.4 \pm 2.3 \mathrm{~m} / \mathrm{s}$ to $11.6 \pm 2.2 \mathrm{~m} / \mathrm{s}(\mathrm{p}=0.19)$ with irbesartan and to $12.4 \pm 2.4 \mathrm{~m} / \mathrm{s}(\mathrm{p}=0.99)$ with lisinopril. After adjustment for $\mathrm{SBP}=150 \mathrm{mmHg}$ this value changed respectively to $11.0 \pm 2.1 \mathrm{~m} / \mathrm{s}(\mathrm{p}=0.02)$ and to $12.2 \pm 2.5 \mathrm{~m} / \mathrm{s}(\mathrm{p}=0.76)$ (Table 2).

PWV (F-D) after 12 weeks of treatment changed from $11.0 \pm 2.6 \mathrm{~m} / \mathrm{s}$ to $10.1 \pm 2.4 \mathrm{~m} / \mathrm{s}(\mathrm{p} \leq 0.05)$ with irbesartan and to $11.4 \pm 1.5 \mathrm{~m} / \mathrm{s}(\mathrm{p}=0.85)$ with lisinopril. After adjustment for $\mathrm{SBP}=150 \mathrm{mmHg}$ this value changed respectively to $10.9 \pm 2.3 \mathrm{~m} / \mathrm{s}(\mathrm{p} \leq 0.05)$ and to $11.7 \pm 2.4 \mathrm{~m} / \mathrm{s}(\mathrm{p}=0.86)$ (Table 2).

\section{Discussion}

This study investigated the effects of two different antihypertensive drugs, lisinopril and irbesartan, on the $\mathrm{PWV}$, an index of arterial compliance, in predominantly elastic compared with predominantly muscular arteries. There was a large BP drop in the patients included in the two groups, which may be due to the fact that both medications were titrated upwards at close intervals although the $\mathrm{BP}$ readings at the end of the 12 weeks were not significantly different statistically between the two. However lisinopril

Table 2 Baseline and end of trial results

\begin{tabular}{|c|c|c|c|c|}
\hline & Baseline & 12 weeks irbesartan & I 2 weeks lisinopril & $\begin{array}{l}\text { p value irbesartan vs } \\
\text { lisinopril }\end{array}$ \\
\hline SBP $(\mathrm{mmHg})$ & $162.4 \pm 12.9$ & $134.5 \pm 14.8^{*}$ & $145.2 \pm 25^{*}$ & 0.08 \\
\hline $\mathrm{DBP}(\mathrm{mmHg})$ & $98.7 \pm 8.1$ & $78.6 \pm 9.2^{*}$ & $84.1 \pm 11.6^{*}$ & 0.08 \\
\hline PWV (CF) (m/sec) & $15.1 \pm 5$ & $13.3 \pm 2.6 * *$ & $14 \pm 4.7^{*}$ & 0.345 \\
\hline $\begin{array}{l}\text { PWV (CF) }(\mathrm{m} / \mathrm{sec}) \text { adjusted } \\
\text { for } \mathrm{SBP}=150 \mathrm{mmHg}\end{array}$ & $14.9 \pm 4$ & $13.6 \pm 3.2 * *$ & $15.6 \pm 4.9 *$ & $0.24 I$ \\
\hline PWV (CR) (m/sec) & $12.4 \pm 2.3$ & $11.6 \pm 2.2$ & $12.4 \pm 2.4$ & 0.126 \\
\hline $\begin{array}{l}\text { PWV }(\mathrm{CR})(\mathrm{m} / \mathrm{sec}) \text { adjusted } \\
\text { for } \mathrm{SBP}=150 \mathrm{mmHg}\end{array}$ & $12.2 \pm 1.9$ & $11.8 \pm 2.4^{*}$ & $12.6 \pm 2.5$ & 0.042 \\
\hline PWV (FD) (m/sec) & $\mathrm{II} \pm 2.6$ & $10.1 \pm 2.4^{*}$ & $1 \mathrm{I} .4 \pm 1.5$ & 0.01 \\
\hline $\begin{array}{l}\text { PWV (FD) }(\mathrm{m} / \mathrm{sec}) \text { adjusted } \\
\text { for } \mathrm{SBP}=150 \mathrm{mmHg}\end{array}$ & $10.7 \pm 1.4$ & $10.9 \pm 2.3 * *$ & $11.7 \pm 2.4$ & $<0.001$ \\
\hline
\end{tabular}

${ }^{*} \mathrm{p}<0.05,{ }^{*} \mathrm{p}<0.01-$ Baseline vs 12 weeks treatment

Abbreviations: SBP, systolic blood pressure; DBP, diastolic blood pressure; PWV (CF), pulse wave velocity carotid-femoral; PWV (CR), pulse wave velocity carotid-radial; PWV (FD), pulse wave velocity femoral-dorsalis. 


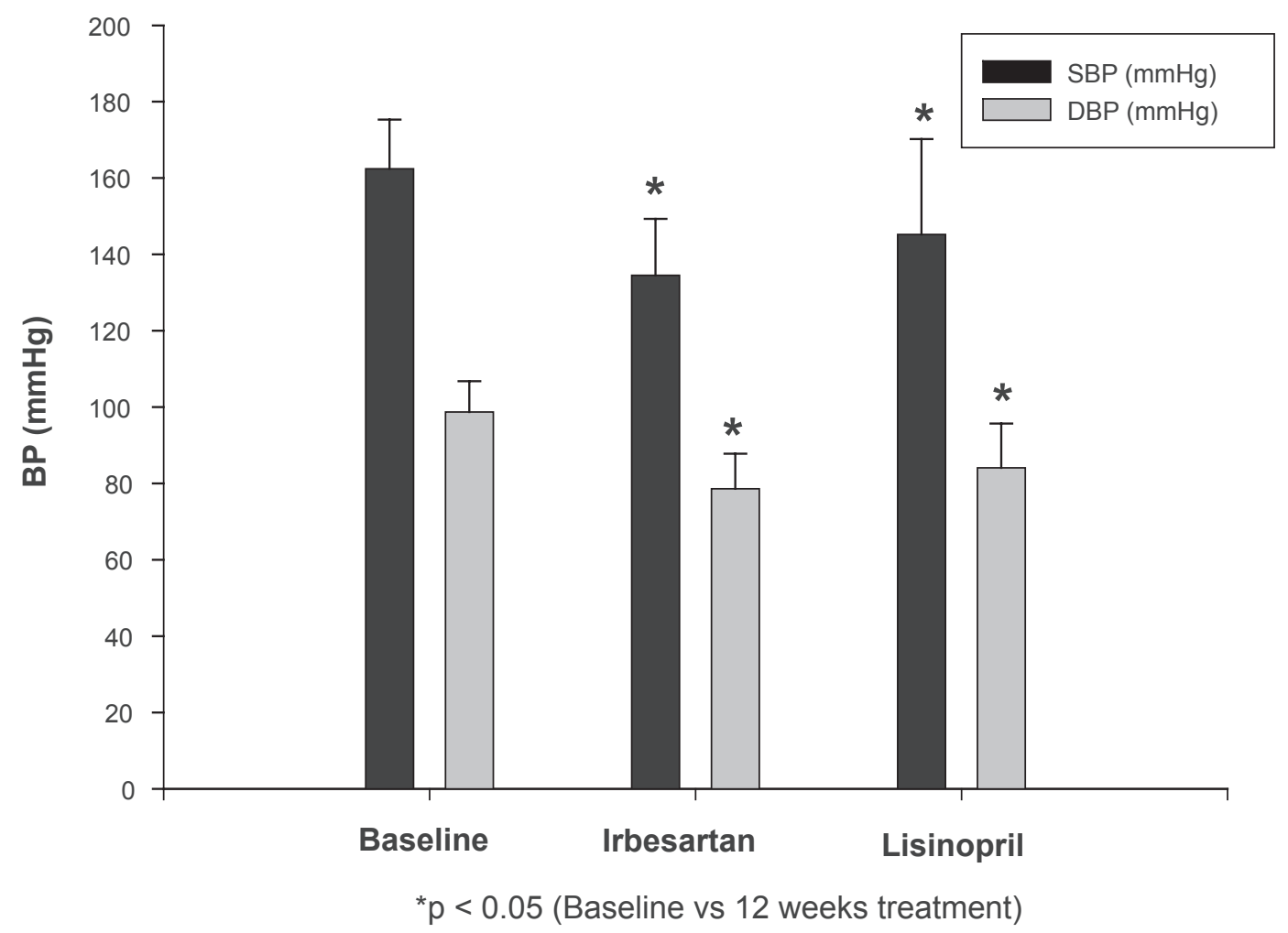

Figure I Blood pressure systolic (SBP) and diastolic (DBP) at baseline and after 12 weeks treatment with irbesartan and lisinopril. The changes are statistically significant for both drugs $(p<0.05)$ for SBP and DBP.

was not titrated to $40 \mathrm{mg}$, which could have resulted in the differences in the BP lowering effects between the two drugs. Recent analysis of the CALM II study showed that lisinopril may have different effects on SBP, DBP and pulse pressure compared to candesartan (an ARB), ${ }^{23}$ and since 24-hour ambulatory BP monitoring was not performed in this study, the observed differences in BP reduction and subsequent differences in PWV need a larger study including 24-hour BP monitoring. However, given the different resultant BP findings at the end of the 12 weeks, and knowing that BP reduction affects vascular compliance, the underlying biologic effects of the two drugs can not be fully explained. A way to address this impact of differences in achieved BP readings would be to titrate both drugs upwards to result in similar BP readings at the end of the study period.

Hypertension is associated with increased arterial stiffness $^{7,8}$ but it is also known that a reduction in BP is associated with an improved arterial compliance. ${ }^{23,24}$ The renin-angiotensin system affects the properties of arteries, both predominantly elastic and muscular. Neutel et al showed that benazepril improved arterial compliance in monotherapy and more efficaciously in combination with amlodipine. ${ }^{16}$ Shargorodsky et al showed the positive effect of prolonged treatment with the AT1 receptor blocker valsartan on the small and large arterial compliance in a group of uncomplicated essential hypertensives. ${ }^{17}$ Only one other study compared the effect of ARBs with ACEIs on arterial compliance, showing a significant decrease in augmentation index and PWV with both drugs, ${ }^{20}$ but did not analyze the effect of these on different types of arteries.

Our results confirm the finding of these previous studies on the PWV, one of the most important measures of arterial compliance. Evaluating the PWV, it has been possible for us compare the effect of these two drugs on different types of arteries. We assessed PWV C-F, PWV C-R and PWV F-D to study different segments of the arterial tree. Our findings confirm the positive effects of irbesartan and lisinopril on improving arterial compliance in elastic vessels. After 12 weeks of treatment for both the drugs the decrease in PWV C-F was statistically significant. This suggests a positive effect of these two drugs in improving the cardiovascular risk, over and above the known effects of lowering BP that were evident and statistically significant in our study.

Similar effects were also seen with irbesartan on the muscular arteries. When on treatment with irbesartan but not when on lisinopril we found a significant decrease in the PWV F-D, suggesting a positive effect of the ARBs on the 
arterial compliance of the muscular vessels. Our finding is important as it was also significant after adjustment for SBP. Correcting for SBP also showed that irbesartan produced a similar effect on the muscular arteries in the carotid-radial region. This suggests that irbesartan improved arterial compliance in the muscular arteries independently of its effect on BP, whereas lisinopril did not.

There are a number of large epidemiological studies showing that different antihypertensive agents have different outcomes. For example in the LIFE trial it was shown that treatment with losartan was more effective than atenolol in reducing cardiovascular morbidity and mortality as well as mortality from all causes in patients with hypertension, diabetes and $\mathrm{LVH}^{25}$

In elderly patients with heart failure the ELITE-I ${ }^{26}$ trial showed better outcomes with an ARB than with an ACEI, showing that treatment with losartan was associated with a lower mortality than that with captopril. This effect was not sustained in the ELITE-II trial. ${ }^{27}$

In our study the different effects of the two drugs on muscular arteries is difficult to explain. The effects may be due to a more specific effect of the ARB on the vascular smooth muscle contraction or due to a difference in release of some endothelial mediators. However, some studies have shown a similar increase in the bioavailability of nitric oxide after treatment with both drugs. ${ }^{28}$ There may be some other properties of the ARBs that explain this finding. There is some evidence that ARBs improve erectile dysfunction in hypertensive men and that that this may not be apparent with an ACEI. ${ }^{29}$ Although there are many possible explanations for the difference, it is clear from our study that the shortterm vascular effects are different. It is not clear if they are sustained over a longer period and a long-term study needs to be carried out. However, it is certain that the effect of these two antihypertensive agents on arteries is different, even after the adjustment for SBP. This may have an important clinical relevance and it may further add to the evidence required to choose antihypertensive agents.

There are a number of limitations of this study. The sample size was small. However, the changes in PWV from the baseline were statistically significant $(23.8 \%$ of reduction in PWV C-F with irbesartan and $10.6 \%$ with lisinopril after adjustment for SBP of $150 \mathrm{mmHg}$ ), despite the small number of patients involved, suggesting the importance of the effect of these two drugs on arterial compliance. It is important to note that PWV is not the only index of arterial compliance and other techniques should be used to confirm our results. However, PWV is known to be one of the most important and commonly used indices of arterial stiffness. A washout period between the two drug regimes at the crossover point of 12 weeks was not carried out, but this would not have influenced the final statistical analysis as the BP readings analyzed were adjusted for SBP of $150 \mathrm{mmHg}$. Arterial compliance was not measured after the 12 weeks period of the study. In such a small sample size, the power to detect any crossover effects may be difficult to establish, and a larger study is needed with adjustment for the carry over effects.

In conclusion, both an ARB and an ACEI improved arterial compliance in the central elastic arteries. Irbesartan improved the vascular compliance also in muscular arteries, suggesting an additive action of this class of drugs, independently of its effect on BP.

\section{Acknowledgments}

We would like to thank Peter Sacares and Winston Banya for their help with the statistical analyses.

Bristol-Myers Squibb provided an educational grant. They had no input in the trial design, day to day running, data collection, analysis or paper writing.

\section{References}

1. National High Blood Pressure Education Program Working Group Report on Hypertension in the Elderly. National High Blood Pressure Education Program Working Group. Hypertension. 1994;23:275-285.

2. Prevention of stroke by antihypertensive drug treatment in older persons with isolated systolic hypertension. Final results of the Systolic Hypertension in the Elderly Program (SHEP). SHEP Cooperative Research Group. JAMA. 1991;265:3255-3264.

3. Dahlof B, Hansson L, Lindholm LH, Schersten B, Ekbom T, Wester PO. Swedish Trial in Old Patients with Hypertension (STOP-Hypertension) analyses performed up to 1992. Clin Exp Hypertens. 1993;15: 925-939.

4. Havlik RJ, LaCroix AZ, Kleinman JC, Ingram DD, Harris T, Cornoni-Huntley J. Antihypertensive drug therapy and survival by treatment status in a national survey. Hypertension. 1989;13:I28-312.

5. Lehman ED, Gosling RG, Sonksen PH. Arterial wall compliance in diabetes. Diabet Med. 1992;9:114-119.

6. Laogun AA, Goslin RG. In vivo arterial compliance in man. Clin Phys Physiol Meas. 1982;3:201-212.

7. Benetos A, Laurent S, Asmar RG, Lacolley P. Large arterial stiffness in hypertension. J Hypertens Suppl. 1997;15:S89-S97.

8. Blacher J, Asmar R, Djane S, London GM, Safar ME. Aortic pulse wave velocity as a marker of cardiovascular risk in hypertensive subject. Hypertension. 1999;33:1111-1117.

9. Cameron JD, Rajkumar C, Christophidis N, Jennings GL, Dart AM. Reduced systemic arterial compliance is associated with left ventricular hypertrophy and diastolic dysfunction in older people. $J$ Am Geriatr Soc. 1997;45:803-808.

10. Lehman ED, Gosling RG, Sonksen PH. Arterial wall compliance in diabetes. Diabet Med. 1992;9:114-119.

11. Guerin AP, Blacher J, Pannier B, Marchais SJ, Safar ME, London GM. Impact of aortic stiffness attenuation on survival of patients in end-stage renal failure. Circulation. 2001;103:987-992.

12. Balcher J, Guerin AP, Pannier B. Impact of aortic stiffness on survival in End-Stage renal disease. Circulation. 1999;99:2434-2439. 
13. Cohn JN. Vascular wall function as a risk marker for cardiovascular disease. J Hypertens. 1999;17:S41-S44.

14. Glasser SP, Arnett DK, McVeigh GE, Finkelstein SM, Bank AJ, Morgan DJ, et al. Vascular compliance and cardiovascular disease: a risk factor or a marker? Am J Hypertens. 1997;10:1175-1189.

15. Wing LM, Reid CM, Ryan P, Beilin LJ, Brown MA, Jennings GL, et al. Second Australian National Blood Pressure Study Group. A comparison of outcomes with angiotensin-converting-enzyme inhibitors and diuretics for hypertension in the elderly. N Engl J Med. 2003;348:583-592.

16. Neutel JM, Smith DH, Weber MA. Effect of antihypertensive monotherapy and combination therapy on arterial distensibility and left ventricular mass. Am J Hypertens. 2004;17:37-42.

17. Shargorodsky M, Leibovitz E, Lubimov L, Gavish D, Zimlichman R. Prolonged treatment with the AT1 receptor blocker, valsartan, increases small and large artery compliance in uncomplicated essential hypertension. Am J Hypertens. 2002;15:1087-1091.

18. von zur Muhlen B, Kahan T, Hagg A, Millgard J, Lind L. Treatment with irbesartan or atenolol improves endothelial function in essential hypertension. J Hypertens. 2001;19:1813-1818.

19. Mahmud A, Feely J. Favourable effects on arterial wave reflection and pulse pressure amplification of adding angiotensin II receptor blockade in resistant hypertension. J Hum Hypertens. 2000;14:541-546.

20. Mahmud A, Feely J. Reduction in arterial stiffness with angiotensin II antagonist is comparable with and additive to ACE inhibition. Am J Hypertens. 2002;15:1092-1095.

21. Senn S. Cross-over trials in clinical research. Chichester: Wiley; 1993. p. 60-69, 100-101.

22. Asmar R, Benetos A, Topouchian J, Laurent P, Pannier B, Brisac AM, et al. Assessment of arterial distensibility by automatic pulse wave velocity measurement: Validation and clinical application studies. Hypertension. 1995;26:485-490.
23. Knudsen ST, Andersen NH, Poulsen SH, et al. Pulse pressure lowering effect of dual blockade with candesartan and lisinopril vs high-dose ACE inhibition in hypertensive type 2 diabetic subjects: a CALML II study post-hoc analysis. Am J Hypertens. 2008;21:133.

24. Khder Y, Bray-Desboscs L, Aliot E, Zannad F. Effects of blood pressure control on radial artery diameter and compliance in hypertensive patients. Am J Hypertens. 1997;10:269-274.

25. Slama M, Safavian A, Tual JL, Laurent S, Safar ME. Effects of antihypertensive drugs on large artery compliance. Neth $J$ Med. 1995;47:162-218.

26. Dahlof B, Devereux RB, Kjeldsen SE, et al. LIFE Study Group. Cardiovascular morbidity and mortality in the Losartan Intervention For Endpoint reduction in hypertension study (LIFE): a randomised trial against atenolol. Lancet. 2002;359:995-1003.

27. Pitt B, Segal R, Martinez FA, et al. Randomised trial of losartan versus captopril in patients over 65 with heart failure (Evaluation of Losartan in the Elderly Study, ELITE). Lancet. 1997;349:747-752.

28. Pitt B, Poole-Wilson PA, Segal R, et al. Effect of losartan compared with captopril on mortality in patients with symptomatic heart failure: randomised trial--the Losartan Heart Failure Survival Study ELITE II. Lancet. 2000;355:1582-1587.

29. Hornig B, Landmesser U, Kohler C, Ahlersmann D, Spiekermann S, Christoph A, et al. Comparative effect of ace inhibition and angiotensin II type 1 receptor antagonism on bioavailability of nitric oxide in patients with coronary artery disease: role of superoxide dismutase. Circulation. 2001;103:799-805.

30. Fogari R, Zoppi A. Effects of antihypertensive therapy on sexual activity in hypertensive men. Curr Hypertens Rep. 2002;4:202-210.
Vascular Health and Risk Management

\section{Publish your work in this journal}

Vascular Health and Risk Management is an international, peerreviewed journal of therapeutics and risk management, focusing on concise rapid reporting of clinical studies on the processes involved in the maintenance of vascular health; the monitoring, prevention and treatment of vascular disease and its sequelae; and the involvement of

\section{Dovepress}

metabolic disorders, particularly diabetes. This journal is indexed on PubMed Central and MedLine. The manuscript management system is completely online and includes a very quick and fair peer-review system, which is all easy to use. Visit http://www.dovepress.com/ testimonials.php to read real quotes from published authors. 